Original Research Article

\title{
Collection and analysis of adverse drug reactions of antiretroviral therapy in a tertiary care hospital in central India
}

\author{
Sandeep Kumar Adwal' ${ }^{1}$ B. L. Bamboria ${ }^{2 *}$, Ashutosh Chourishi ${ }^{1}$, Aditya Bamboria ${ }^{2}$
}

${ }^{1}$ Department of Pharmacology, ${ }^{2}$ Department of Medicine, R.D. Gardi Medical College, Ujjain, Madhya Pradesh, India

Received: 19 April 2018 Accepted: 22 May 2018

*Correspondence to: Dr. B. L. Bamboria, Email: drblbamboria53@ gmail.com

Copyright: (C) the author(s), publisher and licensee Medip Academy. This is an openaccess article distributed under the terms of the Creative Commons Attribution NonCommercial License, which permits unrestricted noncommercial use, distribution, and reproduction in any medium, provided the original work is properly cited.

\begin{abstract}
Background: The main objective of study is to monitor and analyze the adverse drug reactions (ADRs) of ART and to assess causality and severity of the ADRs detected.

Methods: It is a prospective observational study conducted in the ART centre of a tertiary care teaching hospital in central India. The data collected were recorded on standard ADR reporting forms. Causality was assessed by Naranjo's algorithm. Severity of ADR's was assessed by modified Hartwig and Seigel scale. Modified Shumock and Thorton criteria used for preventability assessment.

Results: In twelve months duration 351 patients on ART were observed for ADRs. Total 166 ADRs detected in 96 patients. Incidence of ADRs was slightly more in female. The common systems involved were gastrointestinal $42.77 \%$ followed by nervous system $18.07 \%$, musculoskeletal $15.06 \%$ skin/mucous membrane $07.83 \%$, metabolic and nutritional $04.82 \%$, red blood cell disorders $01.20 \%$, endocrinal $00.60 \%$ and others $09.64 \%$. The causality assessment as per Naranjo's scale showed that out of 166 ADRs, $28.92 \%$ were probable and $71.08 \%$ were possible. Severity assessment by modified Hartwig and Siegel scale showed that $83.34 \%$ ADRs were mild and $15.66 \%$ were moderate. $46.39 \%$ ADRs were probably preventable.

Conclusions: Considering the magnitude of ADR related problems, there is a need for greater awareness among health care professionals, to detect and report them. These ADRs if recognized in time and managed properly can prevent treatment interruption.
\end{abstract}

Keywords: Adverse drug reaction, Antiretroviral therapy, AIDS, HIV, WHO

\section{INTRODUCTION}

HIV/AIDS remains one of the world's most significant public health challenges, particularly in low and middleincome countries. The introduction of highly active antiretroviral therapy (HAART) has led to a significant reduction in AIDS related morbidity and mortality. ${ }^{1,2}$

There is considerable experience in the developed world with the use of antiretroviral medicines. These medicines are associated with significant safety concerns including serious ADRs, with both short and long term effects. The outcome of these long-term adverse effects is unknown.
These unwanted effects are often mild, but sometimes they are more serious and can have a major impact on health or quality of life. On rare occasions, side effects can be life threatening.

Unfortunately, up to $25 \%$ of patients discontinue their initial HAART regimen because of treatment failure (inability to suppress HIV viral replication to below the current limit of detection, 50 copies/ $\mu \mathrm{l}$ ), toxic effects or noncompliance within the first eight months of therapy. 3,4

Once started, antiretroviral treatment must be taken every day for life. Every missed dose increases the risk that the drugs will stop working. It is therefore vital that people 
receiving antiretroviral treatment get all the help they need to minimize the impact of side effects. Often there are several ways to lessen the harm, either by treating the side effects or by switching to alternative antiretroviral drugs.

In 2015 it was estimated that 2.1 million people were living with HIV in India, which equates to a prevalence of $0.3 \% .5$ While this may seem low, because India's population is so large, it is third in the world in terms of greatest number of people living with HIV. Although Madhya Pradesh is still a low prevalence State, the land locked status of the state surrounded by five states with lot of migration and varied socio-cultural constitutions and practices - necessitates close monitoring and implementation of AIDS Control Programme.

In India, often adverse drug reactions (ADRs) go unnoticed or are not reported. Monitoring and reporting of ADRs to HAART in the Indian population is very important. The Indian government has continued efforts to expand access to highly active antiretroviral therapy.

Continuous evaluation of the benefit and harm of ART will help to achieve the ultimate goal of making safer and more effective treatment available to patients. Therefore, many countries have ADRs monitoring centers, which are responsible for collecting, compiling and analyzing any ADRs information reported by health professionals. Based on this information, risk-benefit evaluations are made and safety measures are taken to protect the public from unnecessary harm.

The aim of this study was to gain knowledge on the profile of ADR associated with antiretroviral drugs, the burden of adverse drug reactions of ART in this setup with the ultimate goal of improving the tolerability and effectiveness of HIV treatment.

\section{METHODS}

It is a prospective observational study. This study was carried out in ART centre of tertiary care hospital in central India after the Ethical Committee approval for duration of one year.

The source population consists of HIV-positive cases that were already on ART and who were newly started on ART. Any patient with deliberate or unintended overdose, missing clinical record, incomplete data exclude from the study.

Active pharmacovigilance was adopted. All relevant information recorded in ADR reporting form obtained from CDSCO website. ${ }^{6}$

Cases were further analyzed for drug regimens associated with ADRs and their causality and severity assessment. The Naranjo adverse drug reaction probability scale was used for Assessment of causality of ADR. ${ }^{7}$ Severity of the reaction was assessed using ADR severity assessment scale: Modified Hartwig and Seigel Scale. ${ }^{8}$ Assessment of Preventability of ADR done by Modified Shumock and Thorton criteria. ${ }^{9}$

\section{RESULTS}

A total of 351 patients on ART observed during the study period. A total of 166 ADRs were collected from 96 patients because some patients must have more than one ADRs There were more male $60.40 \%(n=212)$ compared to the female group $39.60 \%(n=139)$.

Out of 351 patients, 96 developed ADRs with an overall incidence of $27.35 \%$. More numbers of female patients with ADRs $(53.13 \%)$ were detected as compared to male patients $(46.87 \%)$. Maximum numbers of patients with ADRs were observed in age group 31-40 years (33.33\%) (Table 1).

Table 1: Age and sex wise distribution of patients with ADRs observed.

\begin{tabular}{|lllll|}
\hline Age group & Male & Female & Total & Percentage \\
\hline$<20$ years & 05 & 03 & 08 & $08.33 \%$ \\
\hline 21-30 years & 04 & 11 & 15 & $15.63 \%$ \\
\hline 31-40 years & 15 & 17 & 32 & $33.33 \%$ \\
\hline 41-50 years & 09 & 16 & 25 & $26.04 \%$ \\
\hline 51-60 years & 08 & 04 & 12 & $12.50 \%$ \\
\hline$>60$ years & 04 & 00 & 04 & $04.17 \%$ \\
\hline $\begin{array}{l}\text { Total } \\
\text { (Percentage) }\end{array}$ & 45 & 51 & 96 & $100 \%$ \\
\hline
\end{tabular}

In this study one adverse event seen in $41.67 \%$ patients, 2 3 in $54.25 \%$ patients and $>3$ in $2.08 \%$ patients in total patients observed with ADRs (Table 2).

Table 2: Adverse Drug Reactions - frequency.

\begin{tabular}{|c|c|c|c|c|c|c|c|}
\hline \multirow[b]{2}{*}{$\begin{array}{l}\text { Frequency- } \\
\text { Adverse } \\
\text { events }\end{array}$} & \multicolumn{7}{|l|}{ Regimen } \\
\hline & $\begin{array}{l}\text { AZT + 3TC } \\
+ \text { NVP } \\
(n=56)\end{array}$ & $\begin{array}{l}\mathrm{d} 4 \mathrm{~T}+3 \mathrm{TC} \\
+\mathrm{NVP} \\
(\mathrm{n}=29)\end{array}$ & $\begin{array}{l}\text { TDF + 3TC } \\
+ \text { NVP } \\
(n=2)\end{array}$ & $\begin{array}{l}\mathrm{AZT}+ \\
3 \mathrm{TC}+ \\
\mathrm{EFV}(\mathrm{n}=2)\end{array}$ & $\begin{array}{l}\text { d4T + } \\
3 \mathrm{TC}+ \\
\operatorname{EFV~}(n=5)\end{array}$ & $\begin{array}{l}\text { TDF + 3TC } \\
+ \text { EFV } \\
(n=2)\end{array}$ & Total $(n=96)$ \\
\hline $1 \mathrm{AE}$ & 20 & 16 & 0 & 2 & 0 & 2 & $40(41.67 \%)$ \\
\hline $2-3 \mathrm{AE}$ & 34 & 13 & 2 & 0 & 5 & 0 & $54(56.25 \%)$ \\
\hline$>3 \mathrm{AE}$ & 2 & 0 & 0 & 0 & 0 & 0 & $02(02.08 \%)$ \\
\hline
\end{tabular}

AZT: Zidovudine / d4T: Stavudine / TDF: Tinofavir

3TC: Lamivudine / NVP: Nevirapine / EFV: Efavirenz 
Most common organ system involved was gastrointestinal tract $(42.77 \%)$ followed by nervous system $(18.07 \%)$.
Most commonly observed ADR was nausea (18.07\%) (Table 3).

Table 3: Organ system involved in ADRs, types of ADRs, the number of times they were reported during ART with commonly involved drug regimens.

\begin{tabular}{|c|c|c|c|c|c|c|c|c|}
\hline \multirow[b]{2}{*}{ Types of ADRs } & & \multicolumn{7}{|c|}{ Regimen } \\
\hline & & $\begin{array}{l}\text { AZT+ } \\
\text { 3TC+ } \\
\text { NVP }\end{array}$ & $\begin{array}{l}\text { d4T+ } \\
\text { 3TC+ } \\
\text { NVP }\end{array}$ & $\begin{array}{l}\text { TDF+ } \\
\text { 3TC+ } \\
\text { NVP }\end{array}$ & $\begin{array}{l}\text { AZT+ } \\
\text { 3TC+ } \\
\text { EFV }\end{array}$ & $\begin{array}{l}\text { d4T + } \\
\text { 3TC+ } \\
\text { EFV }\end{array}$ & $\begin{array}{l}\text { TDF+ } \\
\text { 3TC+ } \\
\text { EFV }\end{array}$ & $\begin{array}{l}\text { Total } \\
(\mathrm{n}=166)\end{array}$ \\
\hline \multirow{4}{*}{$\begin{array}{l}\text { Gastrointestinal } \\
\text { (GIT) } \\
42.77 \%(71)\end{array}$} & Nausea & 22 & 05 & 02 & 00 & 01 & 00 & $30(18.07 \%)$ \\
\hline & Vomiting & 15 & 02 & 01 & 00 & 01 & 00 & $19(11.45 \%)$ \\
\hline & $\begin{array}{l}\text { Abdominal } \\
\text { pain }\end{array}$ & 11 & 03 & 00 & 00 & 01 & 01 & $16(09.64 \%)$ \\
\hline & Anorexia & 03 & 03 & 00 & 00 & 00 & 00 & $06(03.61 \%)$ \\
\hline \multirow{3}{*}{$\begin{array}{l}\text { Nervous system } \\
18.07 \%(30)\end{array}$} & $\begin{array}{l}\text { Peripheral } \\
\text { neuropathy }\end{array}$ & 00 & 11 & 00 & 00 & 00 & 00 & $11(06.63 \%)$ \\
\hline & Headache & 09 & 02 & 00 & 00 & 00 & 00 & $11(06.63 \%)$ \\
\hline & $\begin{array}{l}\text { Dizziness/ } \\
\text { vertigo }\end{array}$ & 04 & 01 & 00 & 00 & 02 & 01 & $08(04.82 \%)$ \\
\hline \multirow{3}{*}{$\begin{array}{l}\text { Musculo-skeletal } \\
15.06 \%(25)\end{array}$} & Myalgia & 08 & 00 & 00 & 00 & 00 & 00 & $08(04.82 \%)$ \\
\hline & Arthralgia & 03 & 01 & 00 & 00 & 00 & 00 & $04(02.41 \%)$ \\
\hline & Weakness & 03 & 07 & 00 & 00 & 03 & 00 & $13(07.83 \%)$ \\
\hline \multirow{3}{*}{$\begin{array}{l}\text { Skin and appendages } \\
07.83 \%(13)\end{array}$} & Skin rashes & 05 & 02 & 00 & 01 & 00 & 00 & $08(04.82 \%)$ \\
\hline & Pruritus & 02 & 00 & 00 & 00 & 00 & 00 & $02(01.20 \%)$ \\
\hline & $\begin{array}{l}\text { Pigmentation } \\
\text { (Nail) }\end{array}$ & 02 & 01 & 00 & 00 & 00 & 00 & $03(01.81 \%)$ \\
\hline \multirow{2}{*}{$\begin{array}{l}\text { Metabolic and } \\
\text { nutritional disorders } \\
04.82 \%(08)\end{array}$} & Lipodystrophy & 00 & 05 & 00 & 00 & 01 & 00 & $06(03.61 \%)$ \\
\hline & Weight loss & 00 & 02 & 00 & 00 & 00 & 00 & $02(01.20 \%)$ \\
\hline $\begin{array}{l}\text { Red blood cell } \\
\text { disorders } 01.20 \%(02)\end{array}$ & Anemia & 02 & 00 & 00 & 00 & 00 & 00 & $02(01.20 \%)$ \\
\hline $\begin{array}{l}\text { Endocrine disorders } \\
00.60 \%(01)\end{array}$ & Endocrinal & 00 & 00 & 00 & 01 & 00 & 00 & $01(00.60 \%)$ \\
\hline Others $09.64 \%(16)$ & Uneasyness & 11 & 04 & 01 & 00 & 00 & 00 & $16(09.64 \%)$ \\
\hline
\end{tabular}

In GI system most commonly observed adverse drug reaction was nausea followed by vomiting. Most commonly involved drug regimen for GI adverse effect was AZT $+3 \mathrm{TC}+\mathrm{NVP}(71.83 \%)$. There were no GI adverse effects presented with the regimen AZT+3TC+ EFV.

Most commonly observed adverse drug reactions which involved nervous system were peripheral neuropathy and headache. Commonly involved regimens were d4T+3TC+ NVP and AZT + 3TC+ NVP. Peripheral neuropathy which is late adverse effect of ART was detected in 11 patients only with the regimen $\mathrm{d} 4 \mathrm{~T}+3 \mathrm{TC}+\mathrm{NVP}$.

In present study observed adverse effects related to musculoskeletal system were myalgia, arthralgia and weakness. Common regimen involved for these ADRs were $\mathrm{AZT}+3 \mathrm{TC}+\mathrm{NVP}$ followed by $\mathrm{d} 4 \mathrm{~T}+3 \mathrm{TC}+\mathrm{NVP}$ and $\mathrm{d} 4 \mathrm{~T}+3 \mathrm{TC}+\mathrm{EFV}$.
Skin rashes and pruritus were observed in 8 and 2 patients respectively. The most common regimen responsible for these ADRs was AZT + 3TC+ NVP. Pigmentation of nails was also detected in 2 patients on regimen AZT+ 3TC+ $\mathrm{NVP}$ and in 1 patient on regimen $\mathrm{d} 4 \mathrm{~T}+3 \mathrm{TC}+\mathrm{NVP}$.

Metabolic adverse effects commonly found in $\mathrm{d} 4 \mathrm{~T}$ receiving group. In present study 6 patients developed lipodystrophy and 2 patients observed with weight loss. Regimens involved were $\mathrm{d} 4 \mathrm{~T}+3 \mathrm{TC}+\mathrm{NVP}$ and $\mathrm{d} 4 \mathrm{~T}+$ 3TC+ EFV. Two patients developed anemia who were received Zidovudine based regimen AZT+ 3TC+ NVP. Gynaecomastia observed in one patient with regimen $\mathrm{AZT}+3 \mathrm{TC}+\mathrm{EFV}$.

Others side effects like uneasiness observed in 16 patients. Commonly involved regimens were $\mathrm{AZT}+3 \mathrm{TC}+\mathrm{NVP}$ followed by d4T $+3 \mathrm{TC}+\mathrm{NVP}$ and $\mathrm{AZT}+3 \mathrm{TC}+\mathrm{EFV}$. 


\section{Causality assessment of Adverse Drug Reactions}

For causality assessment suspected drug selected from regimen according to their most common ADRs profile described in various literature.

According to Naranjo's scale of ADR causality assessment 28.92\% ADRs were Probable and $71.08 \%$ ADRs were Possible. (Table 4).

Table 4: Causality assessment of the ADRs by Naranjo's algorithm.

\begin{tabular}{|ll|l|}
\hline Causality category & No of ADRs & Percentage \\
\hline Definite ADR & 0 & 0 \\
\hline Probable ADR & 48 & 28.92 \\
\hline Possible ADR & 118 & 71.08 \\
\hline Doubtful ADR & 0 & 0 \\
\hline
\end{tabular}

\section{Severity assessment of Adverse Drug Reactions}

Severity assessment was done by Modified Hartwig and Siegel Scale. Majority of ADRs observed were Mild $(84.34 \%)$. In moderate category total $15.66 \%$ ADRs presented in which $13.85 \%$ were in level 3 and $01.81 \%$ were in level 4b. No severe ADRs were reported (Table 5).

Table 5: Severity assessment of ADRs-Modified Hartwig and Siegel Scale.

\begin{tabular}{|llll|}
\hline Category & & $\begin{array}{l}\text { No. of ADRs } \\
(\mathbf{n = 1 6 6 )}\end{array}$ & Percentage \\
\hline \multirow{2}{*}{ Mild } & Level -1 & 140 & $84.34 \%$ \\
\cline { 2 - 4 } & Level -2 & 00 & 00 \\
\hline \multirow{3}{*}{ Moderate } & Level -3 & 23 & $13.85 \%$ \\
\cline { 2 - 4 } & Level -4a & 00 & 00 \\
\cline { 2 - 4 } & Level -4b & 03 & $01.81 \%$ \\
\hline \multirow{2}{*}{ Severe } & Level -5 & 00 & 00 \\
\cline { 2 - 4 } & Level -6 & 00 & 00 \\
\hline
\end{tabular}

Table 6: Preventability of ADRs- modified Shumock and Thorton criteria.

\begin{tabular}{|lll|}
\hline $\begin{array}{l}\text { Preventability } \\
\text { criteria }\end{array}$ & $\begin{array}{l}\text { Number of } \\
\text { ADRs (n-166) }\end{array}$ & Percentage \% \\
\hline $\begin{array}{l}\text { Definitely } \\
\text { preventable }\end{array}$ & 00 & 00 \\
\hline $\begin{array}{l}\text { Probably } \\
\text { preventable }\end{array}$ & 77 & $46.39 \%$ \\
\hline Not preventable & 89 & $53.61 \%$ \\
\hline Total & 166 & $100 \%$ \\
\hline
\end{tabular}

\section{Preventability of ADRs}

Preventability of reported ADRs was studied using Modified Shumock and Thorton criteria. 53.61\% ADRs were not preventable and $46.39 \%$ ADRs were probably preventable. There were no ADR which was definitely preventable. (Table 6).

\section{DISCUSSION}

Out of 351 patients 96 patients detected with ADRs. Largest number of patients with ADRs was in age group $31-40$ years $(33.33 \%)$. There were more female patients (53.13\%) with ADRs compare to male (46.87\%).

Our findings show that about 1 in every 4 patient $(27.35 \%)$ on ART, reported at least one ADR within a minimum period of less than a month. This incidence rate was less than the study of Ghate et al, in which $35.32 \%$ patient experienced ADRs, Rajesh et al, reported $43.85 \%$ of ADRs whereas AV Kiran Reddy et al, reported $31 \%$ of patients experienced ADRs to ART which was high as compare to our study. ${ }^{10-12}$ Incidence rate in this study was higher than the study of Modayil RR et al, in which the prevalence of ADRs was $17.5 \%$ whereas Henry Namme Luma et al, reported $19.5 \%$ of patients experienced ADRs to ART. ${ }^{13,14}$

These variations in the incidence rate of ADRs may be because of concurrent medications used for treating opportunistic infections and other co-morbid conditions which may results in increase of ADRs incidences.

This difference may be explained by the lack of uniformity in the reporting style of ADRs across settings even though all of the patients in these settings are on similar FDC generic drugs. ${ }^{15}$ However, regional or ethnic susceptibilities to ADRs might also explain this difference.

In this study, the prevalence of ADRs was high in females as compared to male patients. In contrast to this finding, AV Kiran Reddy et al, has found high prevalence of ADRs in males, when compared to females. ${ }^{12}$ In a study Rajesh et al, has found high prevalence of ADRs in females, when compared to males. ${ }^{11}$ The reasons for these sex differences in adverse drug reactions might be due to differences between men and women in body mass index and fat composition, hormonal effects on drug metabolism, or genetic constitutional differences on the levels of various enzymes.

Authors observed that the maximum numbers of ADRs were related to the gastrointestinal system which is in agreement with findings of Modayil et al. ${ }^{13}$ In this study, $42.77 \%$ of the total ADRs related to the gastrointestinal system mainly presented in first 2-4 weeks of therapy. GI related adverse effects included nausea (18.07\%), vomiting (11.45\%), abdominal pain (09.64\%) and anorexia (03.61\%). Cristiane A et al, study reported very high incidence GI adverse events like nausea in 50\%, vomiting in $36 \%$, diarrhoea in $33 \%$ and heartburn in $39 \%$ patients. ${ }^{16}$ Similarly, in the study of Khalili et al, gastrointestinal toxicity was most prominent with incidence rate of $63.7 \% .^{17}$ According to Blake Max et al study the incidence of GI adverse events varies from 4$26 \% .{ }^{18}$ Authors also took many precautions to prevent GI adverse events because these are common cause of nonadherence to drugs and leading to early treatment failure. 
The neurological disorders that were commonly reported $(18.07 \%)$ by patients included peripheral neuropathy $(06.63 \%)$, headache $(06.63 \%)$ and dizziness/vertigo $(04.82 \%)$. Peripheral neuropathy was common in $\mathrm{d} 4 \mathrm{t}$ containing regimen. 11 patients $(11.46 \%$ of total patients with ADRs) developed peripheral neuropathy after 52-72 weeks of ART and all patients received $\mathrm{d} 4 \mathrm{t}$ containing regimen. Similar findings have been reported earlier. ${ }^{19}$ Blake Max et al, study reported that incidence of peripheral neuropathy varies from $13-24 \% .{ }^{18}$ From the study by Browne et al., quoted by Cherry et al, sensory neuropathy was the dose limiting toxicity of $\mathrm{d} 4 \mathrm{~T}$ and that the incidence of sensory neuropathy ( $\mathrm{SN}$ ) related to both the dose and duration of $\mathrm{d} 4 \mathrm{~T} .^{20}$

Apart from it being likely to be caused by chronic ingestion of ARVs, sensory neuropathy (SN) has been recognized as one of the commonest neurological complications of HIV infection since early 1980s. ${ }^{20}$

Myalgia and myopathy were common in AZT containing regimens. Blake Max et al, reported that incidence of myalgia $5-8 \%$ and myopathy $6-18 \% .^{18}$

Rash is the most frequently reported adverse event of the NNRTIs. Carr et al, reported the following incidences of rash: ${ }^{21}$ Nevirapine (17\%), Efavirenz (10\%) and Delavirdine (18\%).According to valentina Montesory et al, approximately $16 \%$ of patients taking Navirapine experience a mild to moderate maculopapular rash within first 6 week of therapy. ${ }^{22}$

In this study, 8 patients experienced rash within 2 weeks of therapy. Out of 8 patients that experienced rash during ART, 7 were treated with Nevirapine containing regimen and 1 Efavirenz containing regimen.

Zidovudine can cause hyperpigmentation of the skin and nail beds and occurs at a much higher incidence in African Americans. $^{23}$ In this study 3 patients developed this adverse effect after 12-24 weeks of therapy. 2 patients received Zidovudine and 1 patient received Stavudine containing regimen. BlakeMax et al, study reported that incidence of Hyperpigmentation of skin and nails common with AZT therapy. ${ }^{18}$

Metabolic adverse reactions were common in NRTI containing regimens particularly in $\mathrm{d} 4 \mathrm{~T}$ containing regimens. Out of 166 ADRs lipodystrophy was reported 6 times, representing $3.61 \%$ in total of the ADRs reported and weight loss was reported 2 times. According to Von Giesen et al, lipodystrophy can present as peripheral fat loss including hollowing of the cheeks, wasting of extremities or flatting of the buttocks (Lipoatrophy), or relative/absolute accumulation of central fat in the abdomen, neck or breasts (Lipo-hypertrophy). ${ }^{24}$

This syndrome has also been observed in a few studies and has been described as a syndrome presenting as a combination of such morphologic and metabolic changes as hyperlipidemia, fat redistribution, and insulin resistance. From the case assessment of these 6 patients that experienced lipodystrophy, all were females. Lipodystrophy occurred more frequently in females as compared to males. A similar finding, although the sample sizes were not the same was observed in a study by Martinez et al. ${ }^{25}$

Out of 96 patients who were experienced ADRs 2 patients $(2.08 \%)$ developed anaemia who were received Zidovudine based regimen AZT $+3 \mathrm{TC}+\mathrm{NVP}$. Cristiane A et al, study study reported anaemia in $8.9 \%$ of patients and in Blake Max et al, study reported that incidence of anaemia ranges from $1-7 \%^{16,18}$

Anaemia can be associated with Zidovudine therapy. The mechanism of Zidovudine myelosuppression is unclear. In vitro it has been suggested that Zidovudine inhibits both erythroid burst-forming units and human granulocytemacrophage colony-forming units. ${ }^{23}$

One male patient with gynaecomastia was detected which was on regimen AZT $+3 \mathrm{TC}+\mathrm{EFV}$. Since the introduction of HAART, a number of cases of gynaecomastia have been reported in $\mathrm{HIV}$-infected men on treatment. ${ }^{26,27}$

The incidence of gynaecomastia in this patient group was $0.8 / 100$ patients /year with a prevalence of 2.8 in those treated longer than 2 years in one study. ${ }^{28}$ Gynaecomastia is not uncommon in HIV-infected men under HAART, especially in those taking Efavirenz and Didanosine.

\section{Causality assessment of Adverse Drug Reactions}

The causality of suspected drug was assessed by using Naranjo's scale of ADR causality assessment. For causality assessment suspected drug selected from regimen according to their most common ADRs profile described in various literature.

Causality assessment of ADRs by Naranjo scale showed that most of the $(71.08 \%)$ ADRs were possible while remaining $(28.92 \%)$ ADRs were probable. None of the ADRs were definite and unlikely. These results are in contrast to the study conducted by Rajesh et al ${ }^{11}$ where majority of $(63.5 \%)$ ADRs were probable. In a study by Av Kiran et $\mathrm{al}^{12}$ most of the $(63.75 \%)$ ADRs were possible.

\section{Severity assessment of Adverse Drug Reactions}

Severity of ADRs was also assessed. Severity is a subjective assessment made by the patient and/or the clinician. Although subjective, it is nevertheless useful in identifying reactions that may affect adherence. ${ }^{29}$

We evaluated the severity of ADRs by Modified Hartwig and Siegel Scale. Majority of ADRs observed were Mild (83.34\%). No serious ADR was observed in this study. Severity does not have the same meaning as seriousness. A patient can experience a severe event that is not serious 
e.g. pruritus. A serious adverse reaction is: any untoward medical occurrence that at any dose results in death, is life threatening, requires or prolongs patient hospitalization, results in persistent disability/incapacity, or is a congenital anomaly/birth defect. (International Conference on Harmonization (ICH)). ${ }^{29}$

\section{Preventability of ADRs}

Preventability of reported ADRs was studied using Modified Shumock and Thorton criteria. 46.39\% ADRs were probably preventable. A similar finding was observed in a study by Mehta et al. ${ }^{30}$ Findings of preventability $(46.39 \%)$ were substantially lower than $(56.76 \%)$ observed in a study conducted by Rajesh et al. ${ }^{11}$ In most of preventable ADRs, preventive measures for ADRs were prescribed or administered to patients: for example, common instructions were given to patients to avoid fatty foods and dairy products for prevention of nausea and vomiting in patients receiving Zidovudine.

\section{CONCLUSION}

ART is becoming increasingly effective, but also increasingly complex. As eradication of the HIV infection is currently not possible, significant problems related to compliance and long-term toxicity can be anticipated with decade-long therapies. Although current antiretroviral regimens are potent from an antiviral perspective, they often fail because of patient nonadherence. To optimize adherence and hence efficacy, clinicians must focus on preventing adverse effects whenever possible, and distinguishing those that are self-limited from those that are potentially serious.

Overall, monitoring of long-term toxicities associated with HIV represents an area of research that is in urgent need of expansion. Indeed, to use medications effectively, we need to understand more precisely the realities of toxicity and the effect of these toxicities on clinical outcomes. Without this understanding, the success of our current therapies can, for a substantial number of individuals, be assumed to be short-lived.

Funding: No funding sources

Conflict of interest: None declared

Ethical approval: The study was approved by the Institutional Ethics Committee (IEC-RDGMC, Ujjain, M.P., Version no.-191)

\section{REFERENCES}

1. Detels R, Munoz A, McFarlane G, Kingsley LA, Margolick JB, Giorgi J. Effectiveness of potent antiretroviral therapy on time to AIDS and death in men with known HIV infection duration. AIDS Cohort Study Investigators. JAMA. 1998;280:1497-503.

2. Hogg RS, Yip B, Kully C, Craib KJP, O’Shaughnessy MV, Schechter MT. Improved survival among HIV- infected patients after initiation of triple drug antiretroviral regimens. CMAJ. 1999;160(5):659-65.

3. Arminio MA, Lepri AC, Rezza G, Pezzotti P, Antinori A, Phillips AN. Insights into the reasons for discontinuation of the first highly active antiretroviral therapy (HAART) regimen in a cohort of antiretroviral naïve patients. I.C.O.N.A. Study Group. Italian Cohort of Antiretroviral-Naïve Patients. AIDS. 2000;14:499507.

4. Lucas GM, Chaisson RE, Moore RD. Highly active antiretroviral therapy in a large urban clinic: risk factors for virologic failure and adverse drug reactions. Ann Intern Med. 1999;131:81-7.

5. HIV AND AIDS IN INDIA. Available at: http://www.avert.org/professionals/hiv-aroundworld/asia-pacific/india

6. Suspected adverse drug reaction reporting formcdsco. Available at: cdsco.nic.in/writereaddata/ADRRF.pdf

7. Naranjo CA, Busto U, Sellers EM, Sandor P, Ruiz I, Roberts EA, et al. Amethod for estimating the probability of adverse drug reactions. Clin Pharmacol Ther. 1981;30:239-45.

8. Hartwig SC, Siegel J, Schneider PJ. Preventability and severity assessment in reporting adverse drug reactions. Am J Hosp Pharm. 1992;49:2229-32.

9. Schumock GT, Thornton JP. Focusing on the preventability of adverse drug reactions. Hosp Pharm. 1992;27:538.

10. Ghate M, Deshpande S, Tripathy S, Nene M, Gedam $\mathrm{P}$, Godbole $\mathrm{S}$, et al. Incidence of common opportunistic infections in HIV-infected individuals in Pune, India: analysis by stages of immunosuppression represented by CD4 counts. Int J Infect Dis. 2009 Jan;13(1):e1-8.

11. Rajesh R, Vidyasagar S, Nandakumar K. Highly active antiretroviral therapy induced adverse drug reactions in Indian human immunodeficiency virus positive patients. Pharmacy Practice (Internet). 2011;9(1):48-55.

12. Reddy AVK, Lihite RJ, Lahkar M, Choudhury U, Baruah SK. A Study on Adverse Drug Reactions In HIV Infected Patients At a ART Centre Of Tertiary Care Hospital In Guwahati, India. Asian J Pharm Clin Res. 2013;6(2):102-4.

13. Modayil RR, Harugeri A, Parthasarathi G, Ramesh M, Prasad R, Naik V, et al. Adverse drug reactions to antiretroviral therapy (ART): an experience of spontaneous reporting and intensive monitoring from ART centre in India. Pharmacoepidemiology and drug safety. 2010;19(3):247-55.

14. Luma HN, Marie-Solange D, Simeon-Pierre C, Elvis $\mathrm{T}$, Gloria A, Achu Joko $\mathrm{H}$, et al. Adverse drug reactions of Highly Active Antiretroviral Therapy (HAART) in HIV infected patients at the General Hospital, Douala, Cameroon: a cross sectional study. P an African Medical Journal - ISSN: 1937- 8688.

15. WHO/Forum for collaborative HIV Research Joint Meeting, ARV drugs adverse events, case definition, grading, laboratory diagnosis and treatment 
monitoring, February 28-29, 2008. Geneva, Switzerland. Available at: http://www.hivforum.org/index.php? option=com_contentandtask $=$ viewandid $=59$ andItemi $\mathrm{d}=102$. Accessed on 16/10/2011.

16. Menezes de Pádua CA, César CC, Bonolo PF, Acurcio FA, Guimarães MDC. Self-Reported Adverse Reactions Among Patients Initiating Antiretroviral Therapy in Brazil. The Brazilian $\mathbf{J}$ of Inf Dise. 2007;11(1):20-6.

17. Khalili H, Dashti-Khavidaki S, Mohraz M, Etghani A, Almasi F. Antiretroviral induced adverse drug reactions in Iranian human immunodeficiency virus positive patients. Pharmacoepidemiol Drug Saf. 2009;18(9):848-57.

18. Max B, Sherer R. Management of the adverse effects of antiretroviral therapy and medication adherence. Clinical Infectious Diseases. 2000;30(2):96-116.

19. Lowe SH, Wensing AM, Hassink EA, ten Kate RW, Richter C, Schreij G, et al. Stavudine but not didanosine as part of HAART contributes to peripheral lipoatrophy: A sub study from the Antiretroviral Regimen Evaluation Study (ARES). HIV Clin Trials. 2007;8:337-44.

20. Cherry CL, McArthur JC, Hoy JF, Wesselingh SL. Nucleoside analogues and neuropathy in the era of HAART. J of Cli Vir. 2003 Feb 1;26(2):195-207.

21. Carr A, Cooper DA. Adverse Effects Of Antiretroviral Therapy. The Lancet. 2000;356(9239):1412-3.

22. Valentina M. Adverse effect of antiretroviral therapy for HIV infection Am Intern Medicine. 1987;107:35.

23. McLeod GX, Hammer SM. Zidovudine: 5 Years Later. Ann Intern Med. 1992;117:487-50.

24. Von Giesen HJ, Hefter H, Jablonowski H, Arendt G. Stavudine and the peripheral nerve in HIV-1 infected patients. J Neurol. 1999;246:211.
25. Martinez E, Mocroft A, Garcia-Viejo MA, PerezCuevas JB, Blanco JL, Mallolas J, et al. Risk of lipodystrophy in HIV-1-infected patients treated with protease inhibitors: a prospective cohort study. The Lancet. 2001;357(9256):592-8.

26. Manfredi R, Calza L, Chiodo F. Gynaecomastia associated with highly active antiretroviral therapy. Annals of Pharmacotherapy. 2001;35:438-9.

27. Paech J, Lorenzen T, von Krosigk A, Graefe K, Stoehr A, Plettenberg A. Gynaecomastia in HIV-infected men: association with effects of antiretroviral therapy. AIDS. 2002;16:1193-4.

28. Piroth L, Grappin M, Petit JM, Buisson M, Duong M, Chavanet $\mathrm{P}$, et al. Incidence of gynaecomastia in men infected with HIV and treated with highly active antiretroviral therapy. Scand J Infect Dis. 2001;3:55960.

29. A practical handbook on the pharmacovigilance of antiretroviral medicines. WHO; 2013:44.

30. Mehta U, Durrheim DN, Blockman M, Kredo T, Gounden R, Barnes KI. Adverse drug reactions in adult medicalin patients in a South African hospital serving a community with a high HIV/AIDS prevalence: prospective observational study. Br J Clin Pharmacol. 2008;65(3):396-406.

Cite this article as: Adwal SK, Bamboria BL, Chourishi A, Bamboria A. Collection and analysis of adverse drug reactions of antiretroviral therapy in a tertiary care hospital in central India. Int J Basic Clin Pharmacol 2018;7:1326-32. 